\title{
Adaptive Control of Servo Motor in "SOTM"
}

\author{
Xiaofeng Xue*, Jian Zheng and Ding Yuan \\ Xi'an Institute of Hi-tech Research, Shaanxi Province, China \\ ${ }^{*}$ Corresponding author
}

\begin{abstract}
The traditional brushless DC motor PID Control of double closed loop has a long adjusting time, large overshoot and especially when the motor model parameters have changed, the motor's control system is unstable. To solve these problems, we propose a speed regulation method based on self-tuning PID control. In the parameter estimator, we use input and output data of the system to identify the corresponding mathematical model according to the recursive least squares algorithm. The design mechanism mainly carries out the solution of the closed-loop feature polynomial, and adjusts the controller parameters adaptively according to the model parameters. Simulation and experimental results show that the proposed control algorithm can effectively overcome the effects of speed and load change, and has the characteristics of fast dynamic response, small overshoot and strong robustness.
\end{abstract}

Keywords - self-tuning PID control, brushless DC motor speed adjustment, recursive least squares algorithm, closed-loop feature polynomial

\section{INTRODUCTION}

Recently, brushless DC motor is widely used in national defense, textile, manufacturing and micro-motor and other fields because of small size, simple structure, high power density, the advantages of large output torque and the rapid development of motor drive system. At present, the the most mature application of brushless DC motor control is the classical double closed-loop control algorithm. However because of brushless DC motor nonlinear, parameter time-varying characteristics, especially when the motor model parameters change, it is difficult to meet the requirements of servo system for control accuracy and control efficiency effect is not satisfactory on the way of classical PID control. So domestic and foreign scholars have designed different controllers. The paper [1] studies the application of Fuzzy PID control algorithm in brushless DC motor, and obtains better control effect, but the control algorithm relies too much on empirical data to make the equipment run unreliable. The paper [2] studies the control algorithm based on the sliding membrane variable structure, but it is easy to cause chattering because of the discontinuous control state. In the paper [3], the Fuzzy Neural network control algorithm is studied, which has a large computational capacity and poor application performance. In the paper [4], the generalized predictive control algorithm is studied, and the control law is designed by identifying the parameters of the controlled object, but the calculation is large when the matrix is inversed. The self-tuning PID control combines classical PID structure with simple, the advantages of strong robustness and the characteristics of self-tuning control. In practice, we don't need to adjust the parameter and the controller on the line changes to enhance the adaptive ability of the controller according to the changes in the parameters.

\section{Mathematical Model of Brushless DC Motor}

Because the output speed of brushless DC motor is controlled, the relationship between output angular velocity and input voltage is deduced from two basic equations of brushless DC motor.

Potential Balance equation:

$$
\begin{gathered}
U(\mathrm{t})=\operatorname{Ri}(t)+L \frac{d i(t)}{d t}+e(t) \\
e(t)=C_{e} \Phi n=C_{e}^{\prime} n
\end{gathered}
$$

Torque Balance equation:

$$
\begin{gathered}
J \frac{d \Omega}{d t}+B \Omega+T_{L}=T_{e m} \\
T_{\mathrm{em}}=C_{T} \Phi i=C_{T}^{\prime} i
\end{gathered}
$$

$\mathrm{U}$ is the bus terminal voltage, $\mathrm{R}$ is the two-phase stator circuit resistance, I is the bus current, e is the back EMF generated by the stator loop, $\mathrm{n}$ is the rotor speed, $C_{e}^{\prime}$ is the motor of the back EMF constant $(\mathrm{V} \cdot \mathrm{s} / \mathrm{rad}), \mathrm{J}$ is the rotor moment of inertia $\left(\mathrm{kg} \cdot \mathrm{m}^{2}\right), \mathrm{B}$ is the system damping coefficient, $\Omega$ is the motor angular speed $(\mathrm{rad} / \mathrm{s}), T_{L}$ is the load torque, $C_{T}^{\prime}$ is the electromagnetic torque constant $(\mathrm{N}$ $\mathrm{m} / \mathrm{A}$ ) of the motor.

We take the laplace trasform to mechanical motion equation (1) and can obtain:

$$
I(\mathrm{~s})=\frac{U(s)-C_{e}^{\prime} \Omega(s)}{L s+R}
$$

We take the laplace trasform to mechanical motion equation (3) and can obtain:

$$
\Omega(s)=\frac{C_{T}^{\prime} I(s)-T_{L}(s)}{J s+B}
$$

The relationship between the output angular velocity $\Omega(s)$ and the input voltage $U$ (s) is removed by substituting (5) and (6) : 


$$
\begin{aligned}
& \Omega(s)=\frac{C_{T}^{\prime}}{J L s^{2}+(J R+L B) s+R B+C_{e}^{\prime} C_{T}^{\prime}} U(s) \\
& -\frac{R+L s}{J L s^{2}+(J R+L B) s+R B+C_{e}^{\prime} C_{T}^{\prime}} T_{L}(s)
\end{aligned}
$$

Ignoring the viscous damping coefficient $\mathrm{B}$, the (7) is further simplified to:

$$
\begin{aligned}
& \Omega(s)=\frac{C_{T}^{\prime}}{J L s^{2}+J R s+C_{e}^{\prime} C_{T}^{\prime}} U(s) \\
& -\frac{R+L s}{J L s^{2}+J R s+C_{e}^{\prime} C_{T}^{\prime}} T_{L}(s)
\end{aligned}
$$

As the motor rotates, the load torque generated by the flywheel is a constant. Because the input voltage is also a constant, we assume:

$$
U(\mathrm{~s})=\lambda T_{L}(s)
$$

if (9) is brought into (8), there is

$$
\Omega(s)=\frac{-\frac{L}{\lambda} s+C_{T}^{\prime}-\frac{R}{\lambda}}{J L s^{2}+J R s+C_{e}^{\prime} C_{T}^{\prime}} U(s)
$$

Converts the formula (10) to the form of a $\mathrm{Z}$ function:

$$
\frac{\Omega(z)}{U(z)}=\frac{b_{1} z^{-1}+b_{2} z^{-2}}{1+a_{1} z^{-1}+a_{2} z^{-2}}
$$

\section{SELF-TUNING PID CONTROLLER}

\section{A. Self-tuning PID Control Principle of Brushless DC Motor}

As shown in Figure 1, the indirect self-tuning PID control system consists of four parts: PID controller, brushless DC motor, object parameter estimator and design mechanism. The inner ring is composed of the controlled object (brushless DC motor) and the controller, in which the PID controller adjusts the value of the controller parameter according to the output of the design mechanism. The outer loop is composed of an object parameter estimator and a design mechanism. The object parameter estimator obtains the system mathematical model mainly according to the input and output data of the controlled object, and the design mechanism adjusts the controller parameters according to the obtained mathematic model. Before the motor running, the initial parameters are roughly estimated according to the parameters on the nameplate of the motor. When the motor running, the object parameter estimator should update the model parameter in each sampling period, meanwhile, the design mechanism calculates the parameter of the controller at the moment. The modeling process in the motor operation and the estimation of the parameters of the controller do not need human intervention, so the ideal closed-loop performance can be obtained.

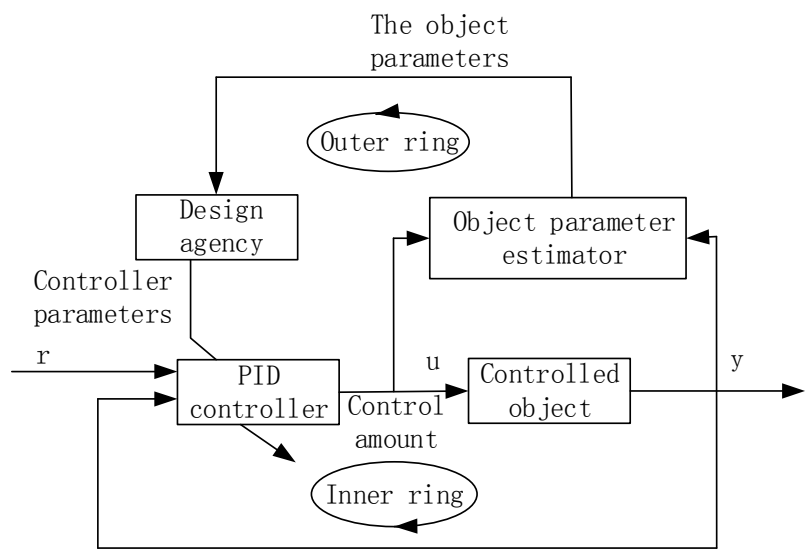

FIGURE I. PRINCIPLE DIAGRAM OF SELF-TUNING PID CONTROL FOR BRUSHLESS DC MOTOR

\section{B. Setting of Control Parameters in Design Mechanism}

For the formula (11), the output angular velocity $\omega(\mathrm{k})$ is substituted with $\mathrm{y}(\mathrm{k})$, and the motor speed loop model can be expressed as:

$$
A\left(\mathrm{z}^{-1}\right) \mathrm{y}(\mathrm{k})=\mathrm{z}^{-d} B\left(\mathrm{z}^{-1}\right) u(\mathrm{k})+v(k)
$$

$\mathrm{y}(\mathrm{k})$ and $\mathrm{u}(\mathrm{k})$ indicate the output angular speed and input voltage of the motor; For external disturbances, for pure delay

$$
\begin{gathered}
A\left(z^{-1}\right)=1+a_{1} z^{-1}+a_{2} z^{-2} \\
\mathrm{~B}\left(z^{-1}\right)=b_{1} z^{-1}+b_{2} z^{-2}
\end{gathered}
$$

For the formula (12), the interference of the constant value is eliminated by the integral, and the PID control can be expressed as:

$$
\mathrm{u}(\mathrm{k})=\frac{\mathrm{R}\left(\mathrm{z}^{-1}\right)}{\mathrm{F}_{1}\left(\mathrm{z}^{-1}\right)} \mathrm{y}_{r}(\mathrm{k})-\frac{G\left(\mathrm{z}^{-1}\right)}{\mathrm{F}_{1}\left(\mathrm{z}^{-1}\right)} y(\mathrm{k})
$$

In the formula:

$$
F_{1}\left(z^{-1}\right)=F\left(z^{-1}\right) \Delta
$$

In the formula, $y_{r}(\mathrm{k})$ is the reference input, $\frac{R\left(\mathrm{z}^{-1}\right)}{F_{1}\left(\mathrm{z}^{-1}\right)}$ is the feedforward compensator, $\frac{G\left(\mathrm{z}^{-1}\right)}{F_{1}\left(\mathrm{z}^{-1}\right)}$ is the feedback compensator.

The closed loop system output is obtained by putting the formula (15) into(12):

$$
y(k)=\frac{R B z^{-d}}{A F_{1}+B G z^{-d}} y_{r}(k)+\frac{F_{1}}{A F_{1}+B G z^{-d}} v(k)
$$


Combining (12) and (17), the structure diagram of the self-tuning PID control system is obtained

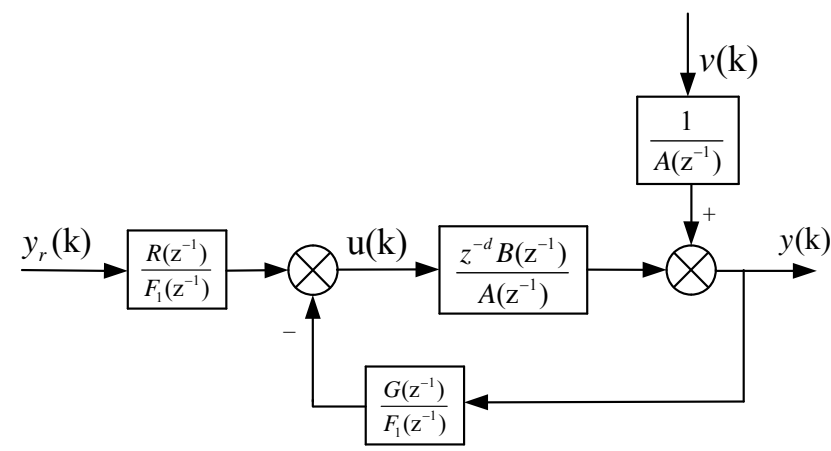

FIGURE II. SELF-TUNING PID CONTROL SYSTEM STRUCTURE DIAGRAM
The closed-loop characteristic equation is the diophantine equation of the following form:

$$
A F_{1}+z^{-d} B G=T
$$

\section{THE SimUlation ANALYSIS}

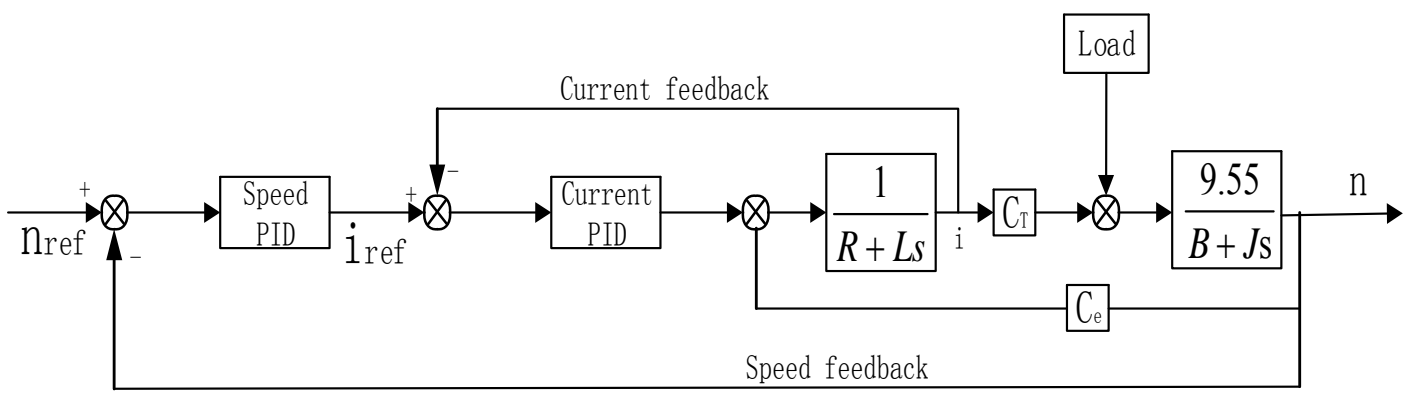

FIGURE III. MOTOR DOUBLE CLOSED LOOP CONTROL SIMULATION SCHEMATIC DIAGRAM

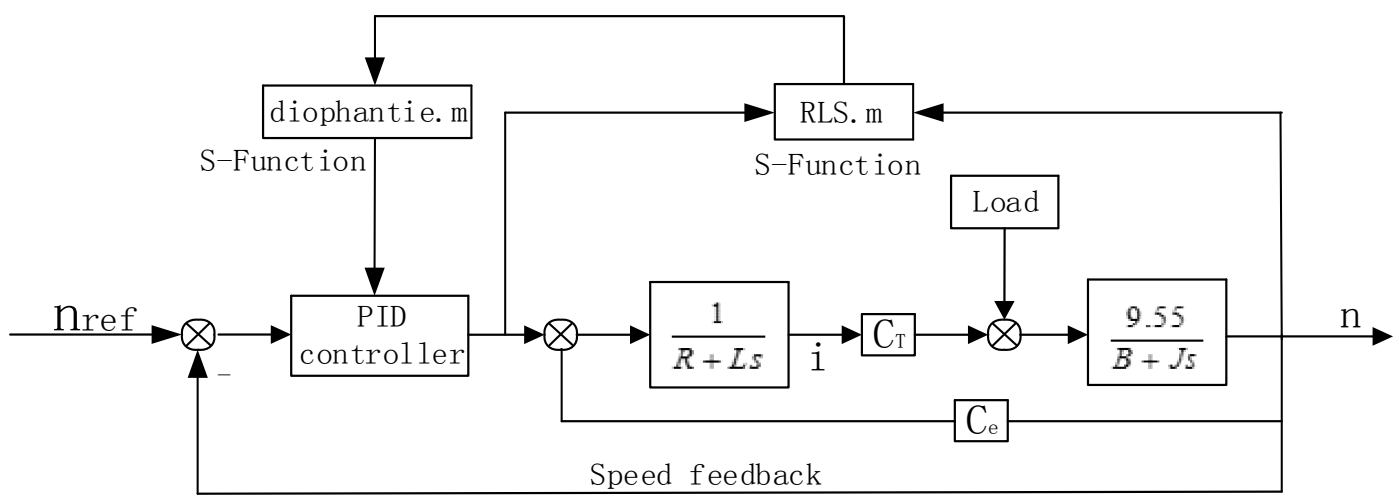

FIGURE IV. MOTOR SELF-TUNING PID CONTROL SIMULATION SCHEMATIC DIAGRAM

Based on the proposed self-tuning PID control strategy, a BLDCM double closed loop speed control model (Figure 4) and a self-tuning PID control model (Figure 5) were built in Matlab/simulink. The simulation research is carried out in two cases of velocity change and load change respectively. The main parameters of the motor are: inductance $1=0.9 \mathrm{mH}, \mathrm{r}=0.33 \Omega$, viscous damping coefficient $\mathrm{B}=0$, magnetic pole $\operatorname{logarithm} \mathrm{n}_{p}=4, J=0.0000189 \mathrm{~kg} . \mathrm{m}^{2}$, torque constant $C_{T}=0.087 \mathrm{~N} . \mathrm{m} / \mathrm{A}$, motor rated voltage $\mathrm{u}=24 \mathrm{v}$, EMF constant $C_{e}=0.0054 \mathrm{~V} / \mathrm{r} / \mathrm{min}$. In Figure 4 , the speed loop pid control parameter are: $K_{p}=0.5, K_{i}=50, K_{d}=0.0005$.
Current loop PID control parameters are: $K_{p}=2, K_{i}=10, K_{d}=0.0001$. In Figure 5, RLS.m identify the parameters of the motor speed loop based on the value of the input voltage and output speed of the motor according to the recursive least squares algorithm; diophantie.m mainly carry out the solution of the closed-loop feature polynomial and adjust the parameters of the controller according to the change of the motor model parameters. Finally adjust the implementation of the control volume $u$ size. 


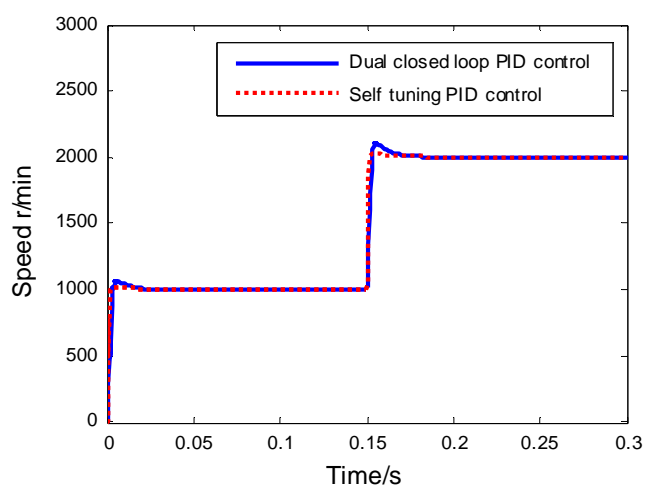

FIGURE V. RESPONSE DIAGRAM FOR A GIVEN VELOCITY CHANGE CONTROL

The initial speed of motor operation is $1000 \mathrm{r} / \mathrm{min}$ and mutate to $2000 \mathrm{r} / \mathrm{min}$ at $\mathrm{t}=0.15 \mathrm{~s}$. Two control algorithm output angular velocity change are shown in Figure 5, from the figure can be seen that the rise time of the angular velocity response in the self-tuning PID control is less than the classical double closed-loop control and the overshoot is smaller. Besides, The speed is more stable, so the control algorithm is more robust to the tracking and robustness of the speed change.

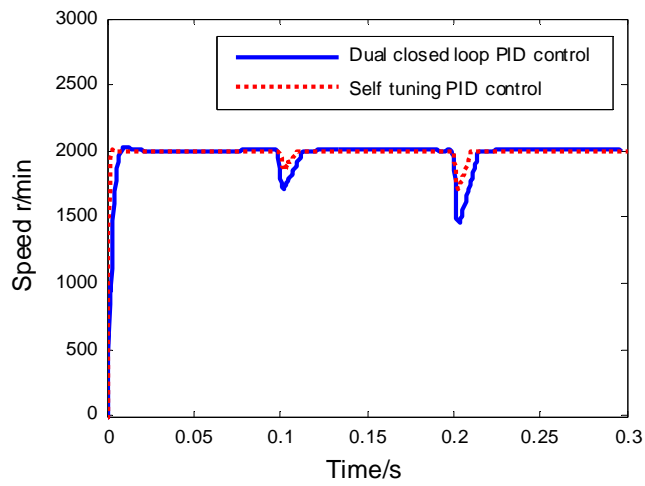

FIGURE VI. LOAD CHANGE CONTROL RESPONSE DIAGRAM

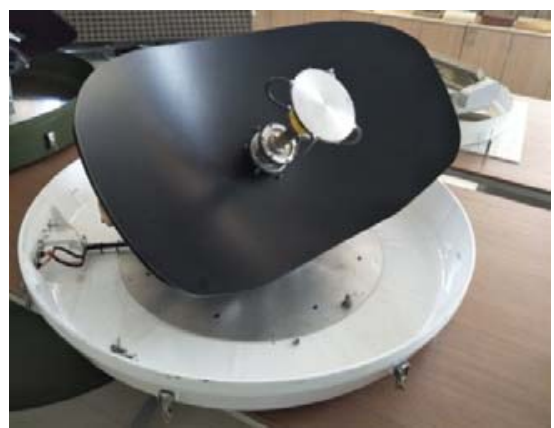

FIGURE VII. "STOM" SERVO ANTENNA TURNTABLE

As the speed response curve of the two control algorithms is shown in Figure 7, the initial motor speed is $2000 \mathrm{r} / \mathrm{min}$ and the load is added at $\mathrm{T}=0.1 \mathrm{~s}$ and $\mathrm{t}=0.2 \mathrm{~s}$ time respectively. It can be seen from the figure 6 that, in the condition of steady state of rotating speed, the maximum disturbance amplitude
$138 \mathrm{r} / \mathrm{min}$ of self-tuning pid control is reduced by $7.1 \%$ than that of classical double closed loop control. The time of restoring steady state is reduced $0.003 \mathrm{~s}$ when adding the load torque of $0.5 \mathrm{~N} . \mathrm{m}$ load torque. After adding the load torque of $1 \mathrm{~N} . \mathrm{m}$, the speed change of self-tuning pid control decreased by $12.6 \%$ compared with classical double closed loop control, and the time of restoring steady state decreased by $0.0045 \mathrm{~s}$. The result shows that the load-resisting ability of self-tuning PID control is better than the traditional double closed-loop control.

\section{EXPERIMENTAL VERIFICATION}

To better validate the effectiveness of the control algorithm, the two control algorithms are validated on the "STOM" experimental platform (figure 7,8), the power supply voltage is $24 \mathrm{~V}$ in the experiment, and the duty ratio is $5 \%$, $10 \%$ and 15 respectively at $\mathrm{t}=0 \mathrm{~s}, \mathrm{t}=0.1 \mathrm{~s}$ and $\mathrm{t}=0.2 \mathrm{~s}$. Figure 9 is the result of the classical double closed loop controlled angular velocity, Figure 11 is the result of the acquisition of the lower angular velocity of the self-tuning PID control. Comparing the two figure to table 1 , we can find that: under the same control algorithm, the higher the output speed of the motor is the smaller the steady-state error will be, which is caused by the fluctuation of the cogging torque of the motor; Under the same duty cycle, the steady-state error of motor speed under self-tuning PID control is smaller than that of classical double closed-loop control, and the rise time of steady state is shorter.

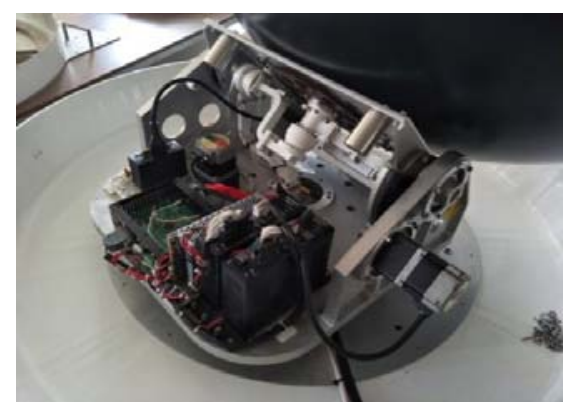

FIGURE VIII. "STOM" SERVO DRIVE SYSTEM

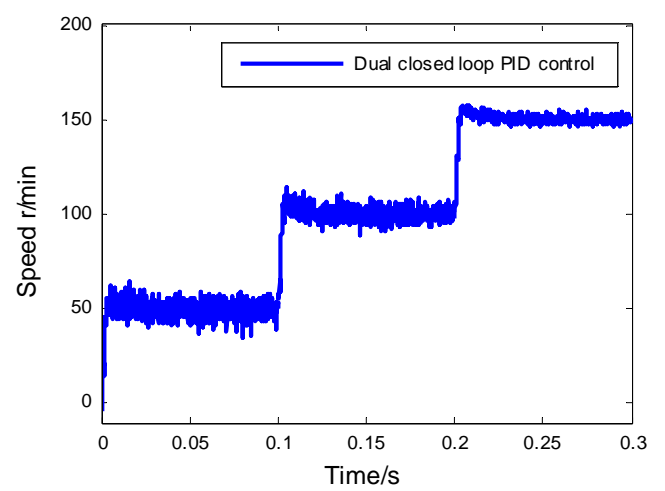

FIGURE IX. DOUBLE CLOSED LOOP CONTROL SPEED FOLLOWING CURVE 


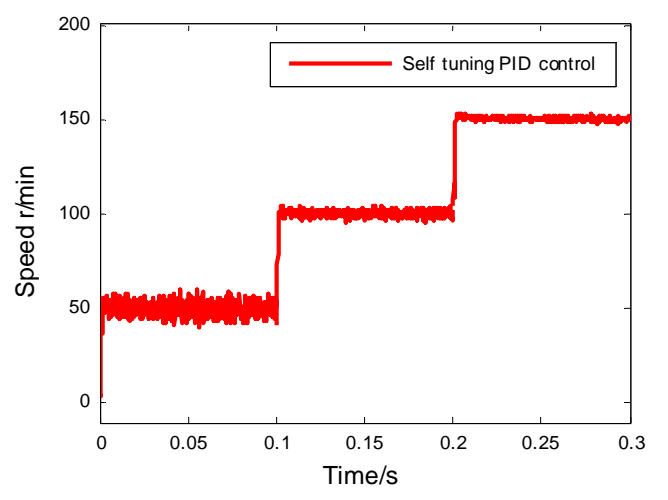

FIGURE X. SELF-TUNING PID CONTROL SPEED FOLLOWING CURVE

TABLE I. DOUBLE CLOSED-LOOP CONTROL AND SELF-TUNING PID CONTROL SPEED FOLLOWING PERFORMANCE ANALYSIS TABLE

\begin{tabular}{|c|c|c|c|c|}
\hline $\begin{array}{c}\text { The control } \\
\text { strategy }\end{array}$ & $50 \mathrm{r} / \mathrm{min}$ & $100 \mathrm{r} / \mathrm{min}$ & $150 \mathrm{r} / \mathrm{min}$ & Rise time \\
\hline $\begin{array}{c}\text { Double closed loop } \\
\text { control }\end{array}$ & $25.8 \%$ & $10.2 \%$ & $3 \%$ & $0.0026 \mathrm{~s}$ \\
\hline $\begin{array}{c}\text { Self-correcting } \\
\text { PID conrrol }\end{array}$ & $18.6 \%$ & $4.8 \%$ & $1.56 \%$ & $0.002 \mathrm{~s}$ \\
\hline
\end{tabular}

\section{CONCLUSION}

For the brushless DC Motor Classic double closed-loop control has a large steady state error. Especially when the motor operating parameters change, the control precision and low control efficiency problem are more sensiable, based on the Self-tuning PID control method, first we introduced the self-tuning PID control design. focusing on the parameter estimator and design mechanism design; Then we built the simulation model of two control algorithms and the simulation results show that the self-tuning PID control is more responsive than the traditional double closed-loop control and more adaptable to speed and load change. Finally, the validity of the proposed control algorithm is validated by comparing the output angular velocity of the two control algorithms under different duty-ratio conditions on STOM.

\section{REFERENCES}

[1] Liu Ming,Song Hong.Adaptive Fuzzy PID Intelligent controller applicate on brushless DC motor in speed control system[J].Motor and control applications, 2012,39:22-25

[2] Xu Jinlong,Zhang Xiangwen.Sliding mode speed control algorithm for brushless DC motor based on integral sliding mode surface [J].Micro-motor, 2014.

[3] Gu Deying, Wu Chengsai, Hou Jiao.BLDCM servo control based on compensated fuzzy neural network [J].Journal of Northeastern University: Natural Science Edition,2013.

[4] Zhang Fan,Zhang Xiangwen. Control simulation of brushless DC motor based on improved generalized predictive control algorithm [J]. Beijing:Journal of Information and Control,2017.

[5] Lu Zhongpei, Yin Huajie.Brushless DC motor control based on linear quadratic optimal PID [J]. Shanghai: Motor and control applications, 2016 .

[6] Guo Wei, Wang Yue, Li Ning,Fu Jianguo. Research on model Reference adaptive speed control of Permanent magnet synchronous motor [J].Xian:Power electronics technology,2016.

[7] Sun Yuliang, Han Changpei,Wang Fei.High Precision Permanent magnet synchronous motor control scheme based on hardware-in-the-loop simulation [J].Shanghai: Motor and control applications, 2016.

[8] Wen Jiabin, Ma Chenwei. Design of Fuzzy PI control system for brushless DC motor [J]. Harbin Polytechnic University: Journal of Motor and Control,2016.

[9] Yin Huaje, Zhou Heng. Sensorless Direct torque control of brushless DC motor [J].Xian:Micro motor,2015. 